\title{
PRINCE ALBERT NATIONAL PARK - AN INVITING WILDERNESS
}

MERV SYROTEUK, Parks Canada, Box 100, Waskesiu Lake, Saskatchewan. SOJ 2 YO

Between the multi-colored, granitic dome of the Canadian Shield and the craggy white peaks of the Canadian Rockies lie the Interior Plains. This vast, level landscape stretches from the south-central United States northward and follows the MacKenzie Valley to the Arctic Ocean. Over most of North America, grasslands and desert vegetation predominate, but from central Saskatchewan northward, the grasslands gradually yield to aspen parkland and finally to boreal forest.

\section{Interpretive Themes}

Owing to the immense size of the park, its complex landscape and the variety of experiences and impressions available to the visitor to Prince Albert National Park, five interpretive themes have been developed. Although they have a tendency to simplify the complexity of the area, these themes capsulize the essence of the park and its significance:

Landscapes of the Southern Boreal Plains

Transition

Boreal Wilderness

Grey Owl

Heritage Resources - Pelicans, Bison and Grasslands

\section{Landscapes of the Southern Boreal Plains}

The Southern Boreal Plains extend from southwestern Manitoba across the prairies to northeastern British Columbia. This ancient landscape began evolving some 500 million years ago with inundation by marine waters forming inland seas. Sedimentation, evaporation and solidification produced limestone and shale, the basement foundation of our present day landscape. This bedrock foundation is now buried beneath glacial drift deposits. The distinguishing features today, are therefore those of a young landscape, one sculptured by its recent icy past.

During the Wisconsin period, the Thunder Hills to the north of the park separated the advancing ice sheet, creating two lobes which gradually engulfed the park area. The western lobe advanced southeastward to create the oriented landforms and drainage patterns found in the Amyot Lake - Sturgeon River area in the southwest corner of the park. The other lobe moved southwesterly to scour out the basins occupied today by Kingsmere and Crean lakes and to create the ice thrust ridges so evident near Hunters Lake.

Evidence of the glacial retreat some $12,000-10,000$ years ago is everywhere. Most impressive are the morainic deposits forming the 'Spruce River Highlands' and the uplands north of the MacLennan River.

It is only to the inexperienced visitor that the park landscape appears similar and monotonous. A variety of glacial landform features consisting of eskers, kettles, kames and recessional moraine adds infinite variety and physical relief. Influenced by glacial deposits and the sorting action of meltwaters, a forest mosaic has developed with aspen uplands, spruce bogs, jack pine ridges and sedge meadows. These form a complex, intricate vegetation pattern, broken by deep channels carved by glacial meltwaters.

\section{Transition}

Another factor making it more difficult to appreciate the forest mosaic typical of the park area is the subtle nature of the transitional change from aspen parkland to boreal forest. Aspen dominates the southern portion of the park, where pockets of fescue grasslands are also found. The 


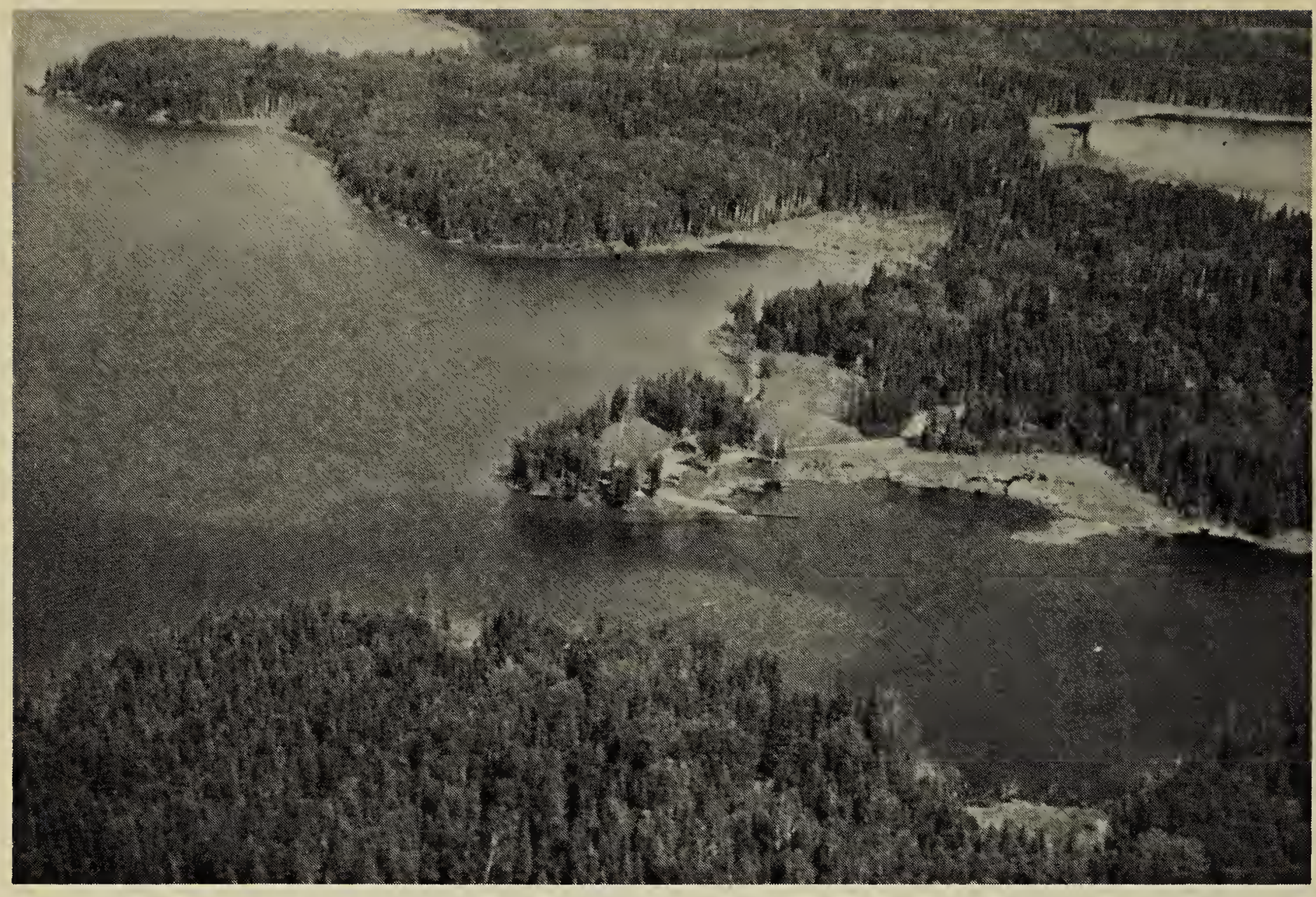

Crean Station, Prince Albert National Park

P. Robinson

boreal landscape is best experienced in the central and northern areas of the park. Representatives of the boreal component are Moose, caribou, wolf and Wolverine; while ground squirrel, Badger and Whitetailed Jack Rabbit can be found in the grasslands and aspen parkland area.

Located on the edge of this great northern forest, Prince Albert National Park is representative of the Southern Boreal Plains, a subdued landscape formed by gentle and gradual processes, by the incursion of marine waters and the gradual sedimentation of these ancient inland seas. It is a landscape with a subtle beauty that tends to calm rather than excite. For this reason people often perceive the park as being subtle with an unassuming character.

This vegetative transition has influenced the cultural and historical use of the park. Archeological evidence suggests a plains culture and forest culture traditionally intermingled in this area during the winter season, dispersing in spring to radically different subsistence patterns. Bison migrated to the shelter of the forest during the harsh winter and together with Moose, Elk, and deer, provided the native population with a source of food.

Only the odd scattered arrowhead, spear point and stone flakes remain as evidence of man's past activities here. The remains of an unimportant fur trading post, the ruins of sawmills and rotting stumps of lumbered trees, overgrown cart trails and disintegrating, shrub-choked foundations of the depression-era work camps are evidence of a period in time when commerce was important in the park area.

The value of this landscape and its significance to the national heritage was not recognized until 1927 when the area was set aside as a national park: a promise to all Canadians that it would remain untouched by man's activities. To many people, Prince Albert National Park in 1927 seemed nothing more than a large tract of land in the wilderness setting of north-central Saskatchewan. But intensive land use practices outside the park have rendered the park area a wilderness island today. Clearcutting pulp operations have encroached 


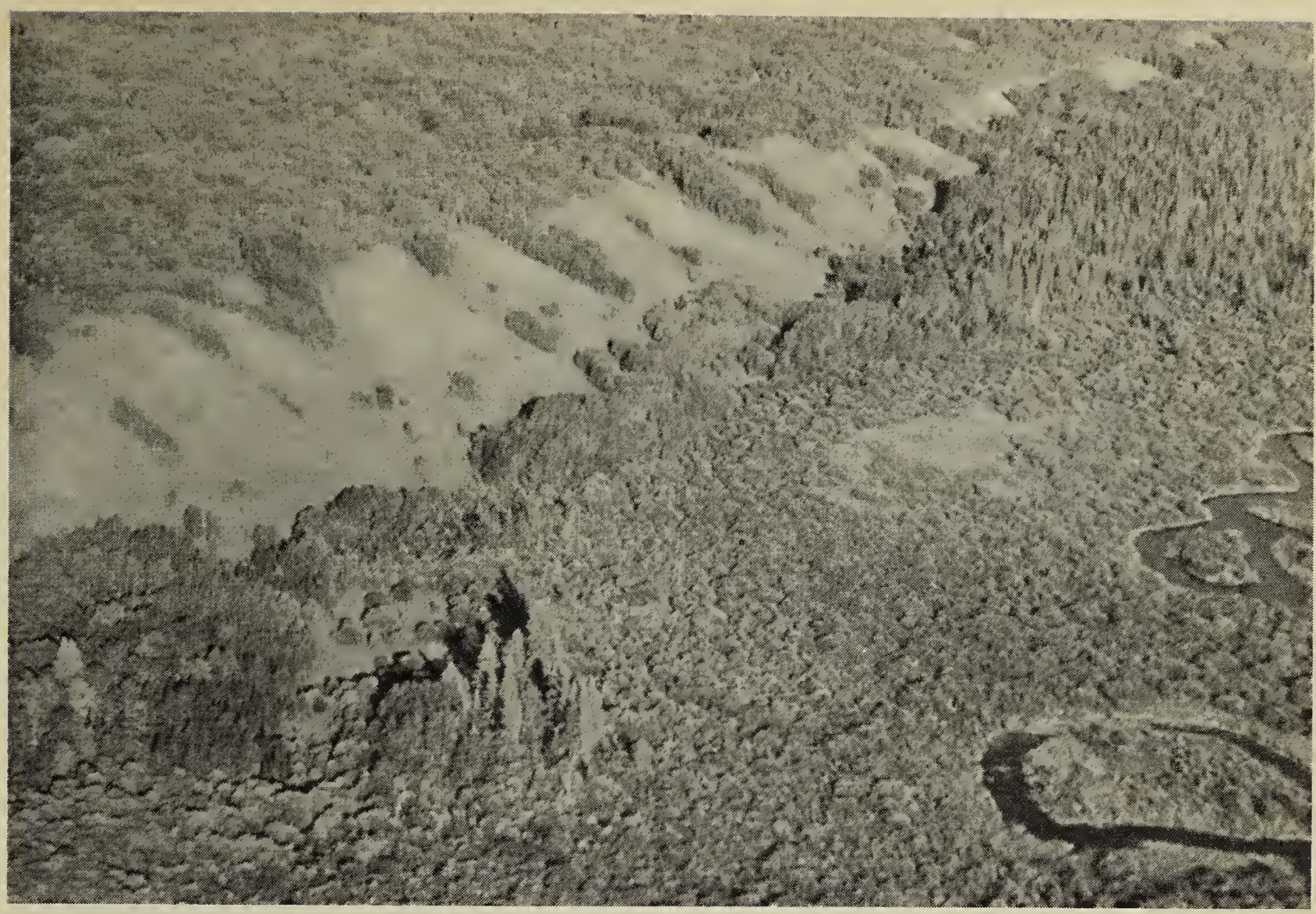

Sturgeon Hillsides

A. Landry

upon the boundaries of the park and farmland fringes the park on the south and west.

\section{Boreal Wilderness}

In spite of these massive landscape changes surrounding it, you can still get the impression of the boreal wilderness when you visit the park. As you travel northward the well defined road patterns and survey system so characteristic of the southern landscape gives way to roads that appear as mere lines wandering through the boreal forest. It is this 'northern image' combined with the vast area of the park $-3,875 \mathrm{~km}^{2}$ - which evoke the feelings of boreal wilderness.

The perception of boreal wilderness is something different for everyone, yet to most it means broad expanses, peacefulness, northern lights, mosquitoes, blackflies and unending silence broken only by the howl of a wolf. These qualities are typical of the boreal wilderness experience in the park today. The vastness and subtle beauty of the back-country are the most im- portant qualities of the boreal wilderness experience. It is an experience that is further fashioned by the forest communities. The aspen uplands give a feeling of an open, friendly wilderness, whereas the spruce forest creates and impression of a dark, closed-in and threating wilderness.

The variety of moods is not confined solely to the impressions created by the character of the forest communities and the vastness of the park, but is also tied closely to the seasons. Transition from one season to the next is not sudden but a gradual fading of one into another as nature casts her spell over the landscape. From the white silence of the boreal winter through to spring with the quiet trickle of water and flights of birds overhead and the arrival of the loon whose haunting call makes known its presence in the northern wilderness, so the seasons blend. Summer is upon us in late June with long warm days, mosquitoes and violent storms. Days shorten to signal the arrival of autumn. The forest mosaic is a blanket of colour and the sounds 


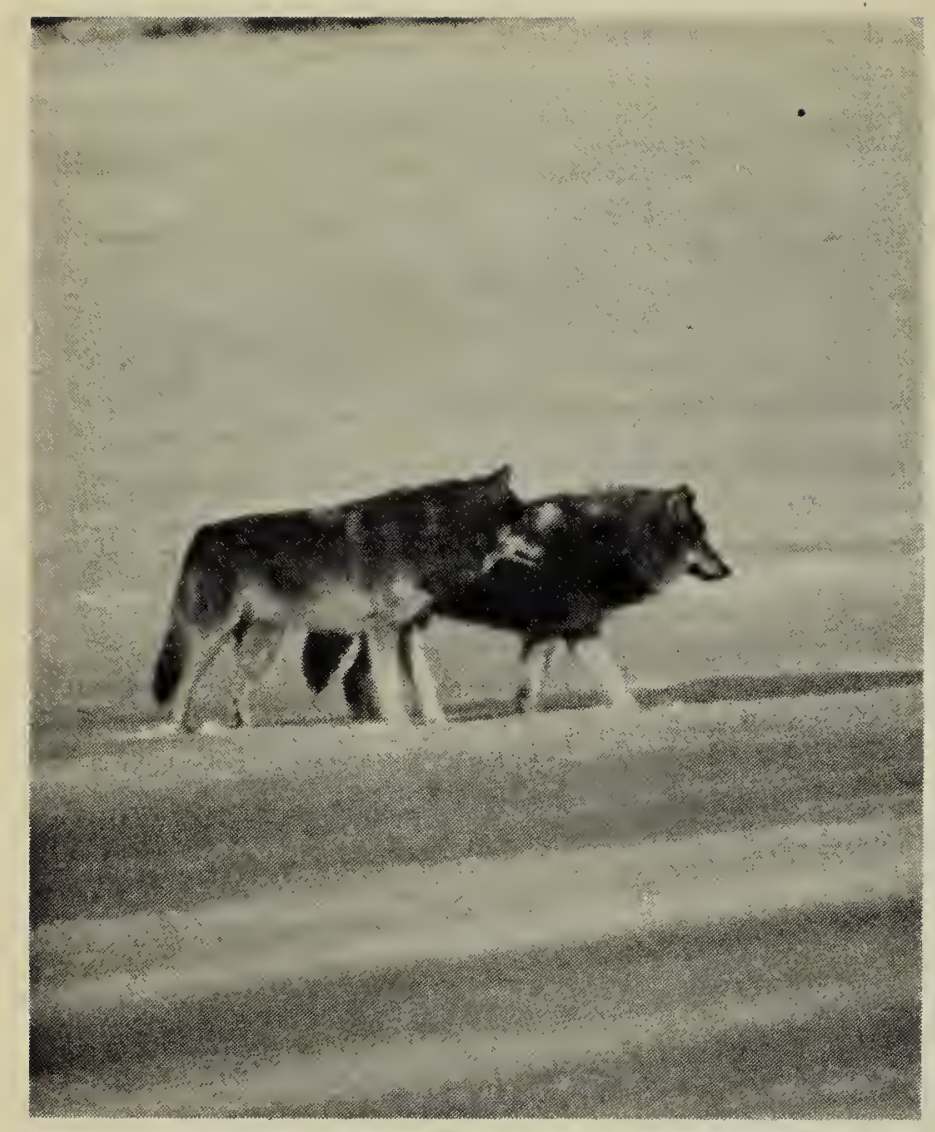

Gray Wolves

M. Syroteuk

associated with a wilderness setting again prevail. The bugling of Elk and howling of wolves make us realize that the park is a special place.

Unfortunately, few visitors experience these changes, for the majority confine their travel to a single season and to the townsite of Waskesiu where the focus is upon recreation; golf, tennis, lawn bowling and the pleasures of a relaxing afternoon on the beach, where the reverberating sounds of music are heard against the wilderness backdrop that surrounds the townsite. As suddenly as the bustling activity of Waskesiu begins in July, it ends in late August and once again the townsite returns to a peaceful state.

\section{Grey Owl}

Inspired by the serenely beautiful and wild landscape, Grey Owl, a gifted orator and author lived at Beaver Lodge on the shores of Ajawaan Lake. Three of his books were completed while at Ajawaan and it was to the peace of Ajawaan that he returned after his lecture tours in Great Britian and the United States. Grey Owl died in 1938.
His primitive log cabin and grave site, Anahareo's cabin and a few plaques remain to remind us of his life here in the park.

\section{Heritage Resources}

Perhaps one of the most significant resources preserved is the American White Pelican colony on Lavallee Lake in the extreme northwest corner of the park. Afforded protection by its Class I zoning status, where access to the colony is allowed only by special permit, the colony has continued to increase in size and is believed to be the second largest colony in Canada today. Here some 7,000 birds return each spring to nest.

The isolated fescue grasslands located in the southwestern portion of the park have continued to increase in significance. It is estimated that about 90 percent of the fescue community has been altered through grazing, ploughing, and haying. Approximately one-third of the existing relict fescue grasslands remaining in Canada is found here. This representation within the park is not only significant because of this community's depletion elsewhere, but also because it is perhaps the northern-most representation of this community in Saskatchewan. The fescue grasslands in the park area are continually being altered by the invasion of aspen suckers and snowberry. To assist in maintaining these grasslands a prescribed burn program is being implemented. This involves the controlled burning of these areas at predetermined intervals.

There are very few locations in Canada where bision are permitted to roam freely. Within the park a herd of 26 animals forage for themselves; migrating seasonally to the fescue grasslands and sedge meadows in the southwest each spring, returning northward each winter to the protection of the boreal forest. The herd's novel beginning was in 1969 when 50 bison were transferred from Elk Island National Park, Alberta to a release site in the Twoforks River area about $80 \mathrm{~km}$. north of the park. The herd 


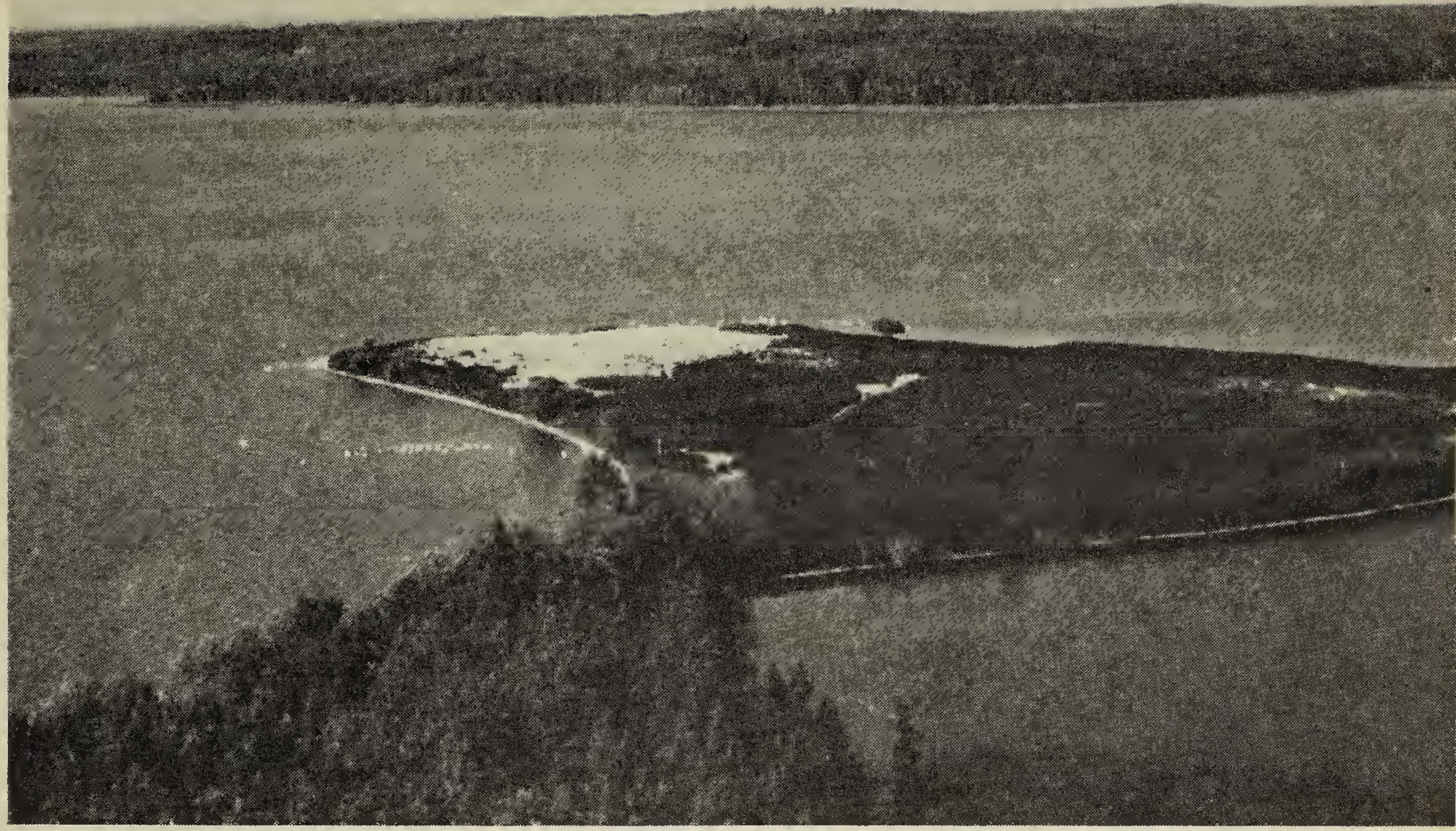

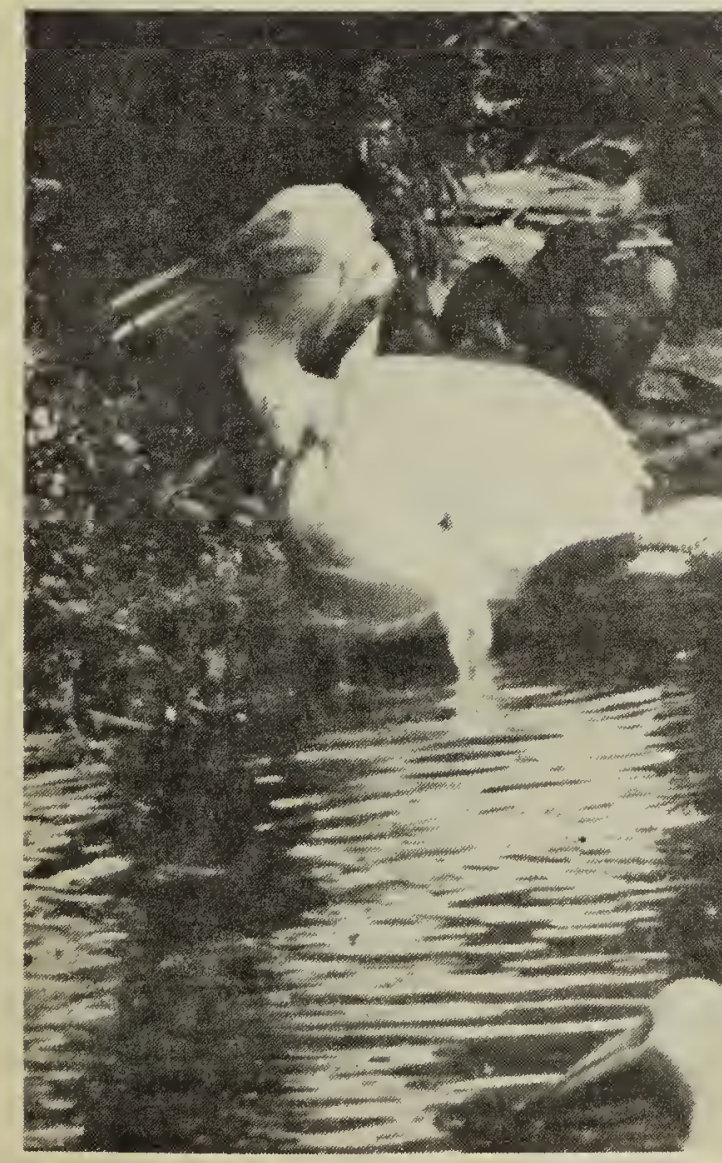

Pelican feeding young

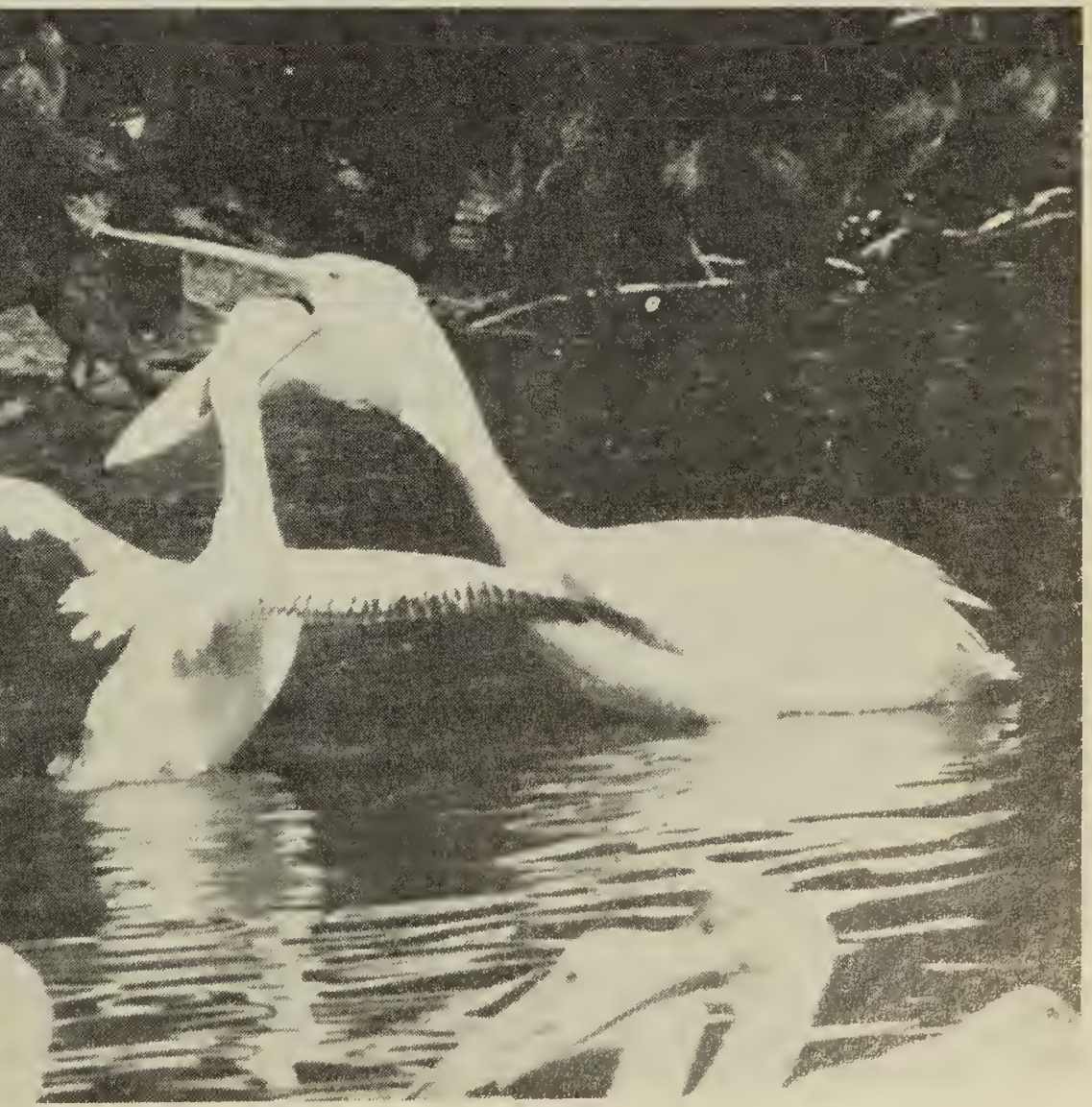

Parks Canada 
dispersed from the release site and three animals migrated to the park. Establishment was slow but now the herd is increasing at a rate of $2-3$ animals annually.

Conclusion

Regardless of the season, whenever you visit the park, take your time, for the sights, sounds and discoveries remain hidden to the hasty traveller and those who confine their exploration to Waskesiu. Remember too, that the monotony of the landscape is only apparent; there are changes, contrast and complexity everywhere. Varied glacial landforms contrast with mosquito-choked muskeg and patches of relict fescue grassland. The character of the landscape is composed of a strong boreal flavour, gradual transition and the silence of wilderness. Grey Owl once said:

We need enrichment other than material prosperity and to gain it we have only to look around at what our country has to offer .... we have something here that no other country has.

I challenge you to experience Prince Albert National park where the structured landscape of man gives way to unstructured, enduring landscape of the northern wilderness. For some, that will entail a backcountry outing, for others a fleeting look at places that still remain wild. Whatever you plan; your enjoyment should be increased by the knowledge that it is yours to enjoy today and will be there for future generations to share tomorrow.

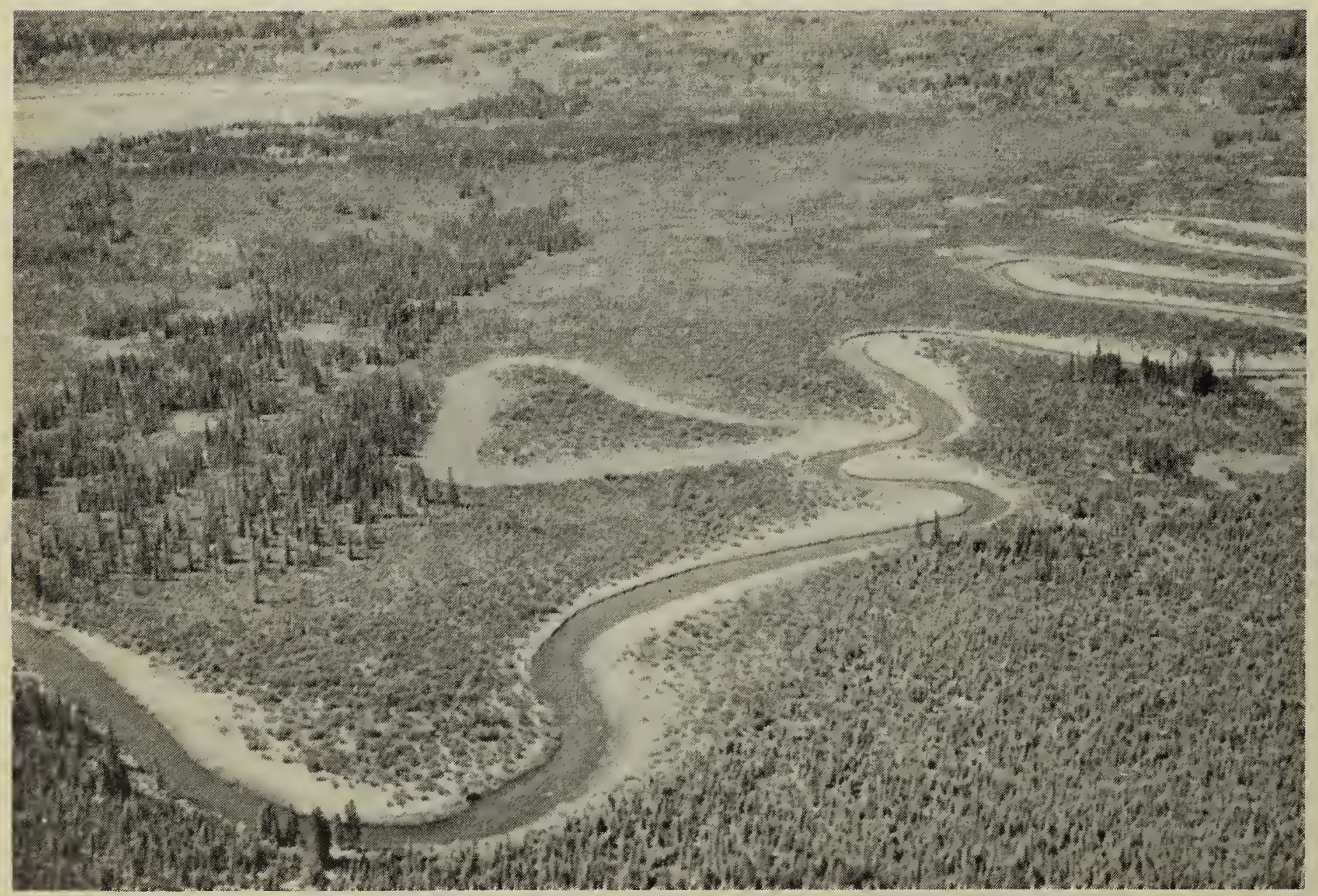

